\title{
MORFOLOGIA E COMPORTAMENTO DAS FORMAS IMATURAS DE Psylotoxus melanospidus GIACOMEL (COLEOPTERA, CERAMBYCIDAE, LAMIINAE) ${ }^{1}$
}

Fioravante Giacomel $^{2}$

\begin{abstract}
MORPHOLOGY AND BEHAVIOR OF THE IMMATURE FORMS OF Psylotoxus melanospidus GIACOMEL (COLEOPTERA, CERAMBYCIDAE, LAMIINAE). Descriptions of larval and pupal stages of Psylotoxus melanospidus Giacomel, 1991 are given. A short account on the biology of species growing in Bauhinia (Leguminosae), is also included.

KEY WORDS. Psylotoxus melanospidus, Cerambycidae, morphology, behavior
\end{abstract}

Na viagem à Chapada dos Guimarães, Mato Grosso, em dezembro de 1983, coletou-se galhos de três essências vegetais, da flora do cerrado, cortados por Psylotoxus melanospidus Giacomel, 1991. Os ramos cortados, de pequenas dimensões que não ultrapassam $50 \mathrm{~cm}$ de comprimento e dois $\mathrm{cm}$ de diâmetro, pertencentes às famílias Myrtaceae e Leguminosae, e desta foi identificado o gênero Bauhinia. Em cada ramo se desenvolveram no máximo quatro larvas, mas com maior freqüência duas. Na medida que crescem, as larvas aumentam gradativamente o diâmetro da galeria, numa extensão de no máximo doze centímetros. Nos últimos ínstares, as larvas roem totalmente o lenho, permanecendo só a casca, bastante rígida. A galeria, aos poucos, é entulhada de serragem e excrementos, exceto o espaço a ser ocupado pela pupa. A larva, sem preparo prévio de uma câmara pupal, passa para o estágio de pupa e assim permanece durante 20 a 30 dias. O imago liberta-se através de um orifício circular ativamente aberto nas paredes do local de empupamento.

As formas imaturas foram fixadas em Kahle-Dietrich e depositadas no Departamento de Zoologia da Universidade Federal do Paraná, bem como o holótipo e os parátipos da espécie descrita pelo autor. As medidas do texto são dadas em milímetros e as escalas das fotografias em micra. As fotografias de varredura foram feitas no Centro de Microscopia Eletrônica da Universidade Federal do Paraná.

\section{LARVA}

Diagnose. Semiretilínea, podendo apresentar leve curvatura e com o abdome pouco mais distendido do que o tórax. Comprimento total da larva

1) Contribuição número 773 do Departamento de Zoologia, Universidade Federal do Paraná.

2) Departamento de Zoologia, Universidade Federal do Paraná, Caixa Postal 19020, 81531-970 Curitiba, Paraná, Brasil. 
quatro vezes a do tórax; cabeça mais da metade inclusa no protórax; placa pronotal branca leitosa, duas vezes mais larga do que longa, provida de numerosos micro-sulcos longitudinais; mesotórax com ampola dorsal; metatórax com ampolas dorsal e ventral; abdome com dez segmentos aumentando gradativamente em comprimento do primeiro ao nono e o décimo trilobado; ampolas presentes nos sete primeiros segmentos. Coloração geral esbranquiçada, exceto as mandíbulas, uma faixa peribucal, sutura hipostomal, enegrecidas; uma faixa amarelada transversal anterior à placa pronotal. Pilosidade esparsa e diminuta.
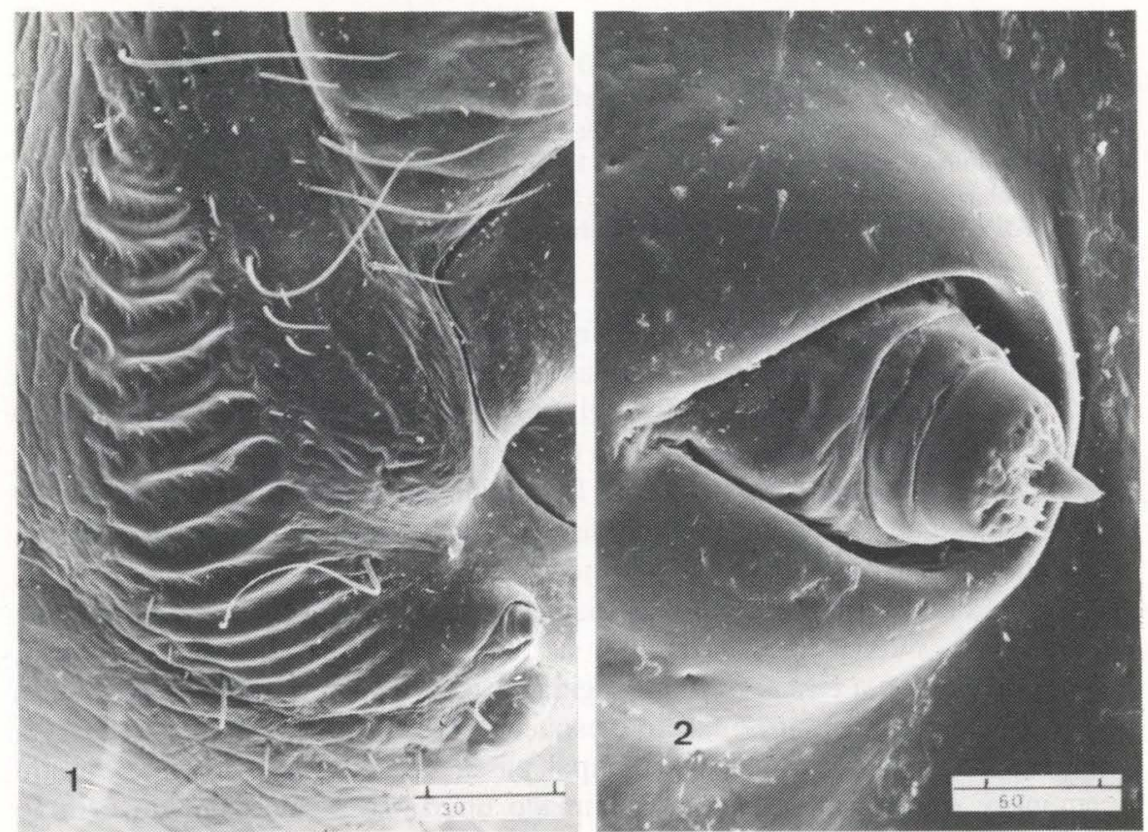

Figs 1-2. Larva de P. melanospidus. (1) Placa estriada frontal; (2) antena e alvéolo antenal.

Medidas. Comprimento total 25,0; comprimento do tórax 6,3; altura do mesotórax 6,0; largura do mesotórax 7,3; comprimento da placa pronotal 3,0; largura da placa pronotal 7,0; altura da cabeça 2,5; largura da cabeça 4,5.

Descrição. Cabeça longa, uma vêz e meia a largura e seis vezes a altura; labro semicircular, lentiforme, com numerosas cerdas de diversos tamanhos; em cada lado, longitudinalmente, uma linha enegrecida, começando na articulação e afundando para a hipofaringe. Escutelo trapezoidal, acentuadamente mais largo do que longo e base mais larga do que o ápice; superfície glabra, semilisa, pouco curva, com pelo menos dois sulcos longitudinais em cada lado e vilosidades curtas e transversais na base da região mediana. Fronte e epicrânio fusionados, com as suturas frontais pouco nítidas e as medianas conspícuas e 
pouco enegrecidas; tentório pouco enegrecido e localizado aquém da metade do comprimento da cabeça placa pré-clipeal arqueada com vilosidades irregulares e transversais; placas estriadas com 17 carenas mais longas e delgadas nos extremos, curtas e robustas próximo à linha mediana (Fig. 1); o restante da fronte, com vilosidades disformes; tubérculos frontais proeminentes e esferoidais; alvéolos antenais em fístula; antenas diminutas e biarticuladas com a membrana basal cuneiformes, segmento basal anelar e o distal cilindriforme com uma coroa de microprocessos circundado um maior central (Fig. 2). Sete pares de cerdas, dois sobre a articulação do clípeo, um intermediário, mais próximo à linha mediana, um na base dos tubérculos frontais, dois na parte interna das placas estriadas e o sétimo entre os tubérculos frontais e a fístula antenal. Mandíbula (Fig. 3) em vista dorsal, pouco mais longa do que a largura da base; superfície semi-lisa, pouco abaulada; área de corte com dois dentes; carena interna terminando no ângulo do dente inferior; articulação cefálica nítida; fóvea semi-arredondada com o ombro pouco elevado; em vista lateral, superfície de textura heterogênea; forame mediano oblíquo em relação à superfície; microestriações próximas ao forame; pelo menos dez cerdas subasais, todas implantadas em alvéolos individuais, sendo duas maiores do que as demais; rótula esférica, ruiva, brilhante e pouco transparente; frênulo proeminente, com um sulco envolvente. Vista interna: face inferior falciforme com superfície microgranulada; ápice agudo e enegrecido; base semiplana com a elevação peduncular em destaque; face interna com as arestas laterais semiparalelas; área apical escavada com vilosidades disformes e uma robusta crista enegrecida, começando no ápice, atravessa diagonalmente toda a área interna e termina junto à aresta superior; área basal intumescida com vilosidades semiparalelas longitudinais. Genas convexas, áreas malares enegrecidas; ocelos salientes e pigmentados; várias cerdas nas imediações das área malares, duas maiores, três medianas e as demais reduzidas em cada lado. Forame occipital único, arredondado e com os bordos anteriores levemente esclerotinizados; área hipostomal semiplana com rugosidades irregularmente distribuídas; sutura mediana visível e as hipostomais esclerotinizadas; faixa malar enegrecida até próximo à sutura mediana. Submento e cardos formando uma peça única quatro vezes mais larga do que longa e de contorno bem definido; mento cilíndrico levemente mais longo no centro; premento com as estipes labiais intumescidas lateralmente; palpos biarticulados, com artículo basal cilindriforme e o distal digitiforme, provido de várias sencilas numa área plana distal; lígula globosa e tão longa quanto os palpos. Estipe maxilar mais largo do que longo; palpígero mais longo do que largo; lacínea digitiforme e articulada; palpos triarticulados, com artículo basal mais robusto, tão longo quanto largo, o mediano mais estreito e mais curto do que o primeiro e o distal digitiforme, mais longo do que largo, provido, distalmente, de sencilas semelhantes às do palpo labial (Fig. 4). Pigmentação ruiva nos estipes, palpígeros, base das lacíneas e todos os segmentos dos palpos. Pilosidade: farta na lígula e lacínias, em forma de corôa no ápice dos estipes, palpígeros e nos artículos dos palpos, exceto os distais.

Tórax com os três segmentos perfeitamente definidos; o primeiro mais 

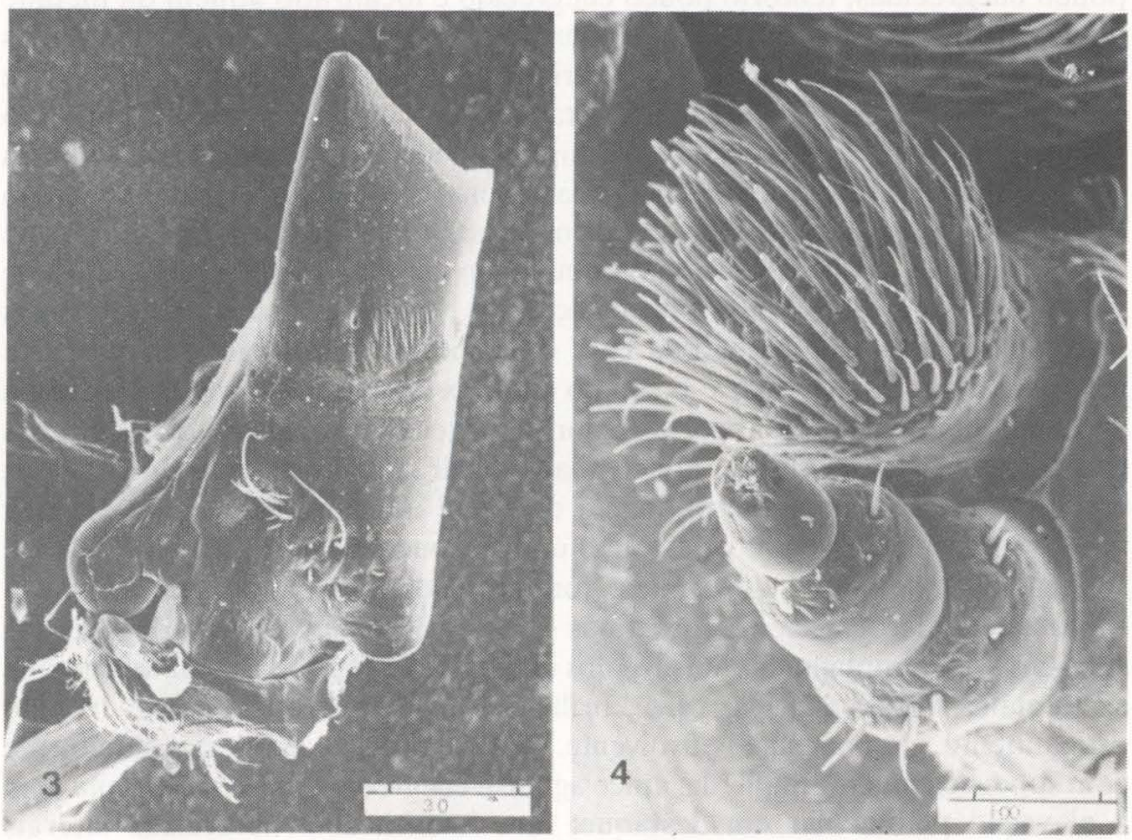

Figs 3-4. Larva de P. melanospidus. (3) Vista lateral da mandibula; (4) palpo maxilar e lacínia.

longo, o segundo e o terceiro menores e subiguais. Pronoto com uma faixa transversal anterior amarelada, placa pronotal trapezóide, mais larga do que longa, esbranquiçada, com numerosos micro-sulcos longitudinais (Fig. 5). Mesonoto pouco mais rebaixado com algumas vilosidades longitudinais. Metanoto provido de ampola com duas fileiras transversais de tubérculos moniliformes separados por um sulco. Prosterno com o presterno arredondado; euesterno trianguliforme e esternelo em faixa transversal mais larga do que longa. Mesosterno, o mais curto, com a ampola pouco definida e tubérculos disformes. Metasterno pouco mais curto do que o prosterno e mais intumescido do que o mesosterno; ampola bem definida e semelhante a ampola dorsal. Espiráculos com o maior diâmetro semiperpendicular, peritrema recortado, ostíolo revestido por tufos de micropilosidade. Pilosidade diminuta e generalizada, pouco mais concentrada no eusterno. Tegumento com faixa amarelada no pronoto e próximo às ampolas; superfície aparentemente lisa, mas com maiores aumentos aparecem, próximo às articulações torácicas e abdominais, numerosos espinhos placóides, equidistantes e com as arestas serrilhadas (Fig. 6a).

Abdome com dez segmentos, os oito primeiros com espiráculos e discos pleurais, estes com ampolas dorsais e ventrais; os cinco primeiros segmentos crescendo gradativamente em comprimento, o sexto e o sétimo subiguais e do mesmo comprimento do quarto; o oitavo e o nono do mesmo comprimento do 
segundo; o décimo reduzido a uma placa distal, onde se abre o ânus em forma de (T). Ampolas (Fig. 6) intumescidas, com pelo menos duas fileiras de tubérculos moniliformes, separados, transversamente, por um sulco; as mais posteriores, especialmente as dorsais com alguns tubérculos a mais, próximo à linha mediana. Espiráculos ruivos, menores do que os mesotoráxicos, semiperpendiculares, diminuindo de tamanho do primeiro ao último, peritrema recortado com o interior atapetado por tufos de micropilosidade (Fig. 7). Tegumento esbranquiçado; pilosidade generalizada curta e rarefeita, exceto as ampolas glabras; microescamas placóides próximas às articulações.
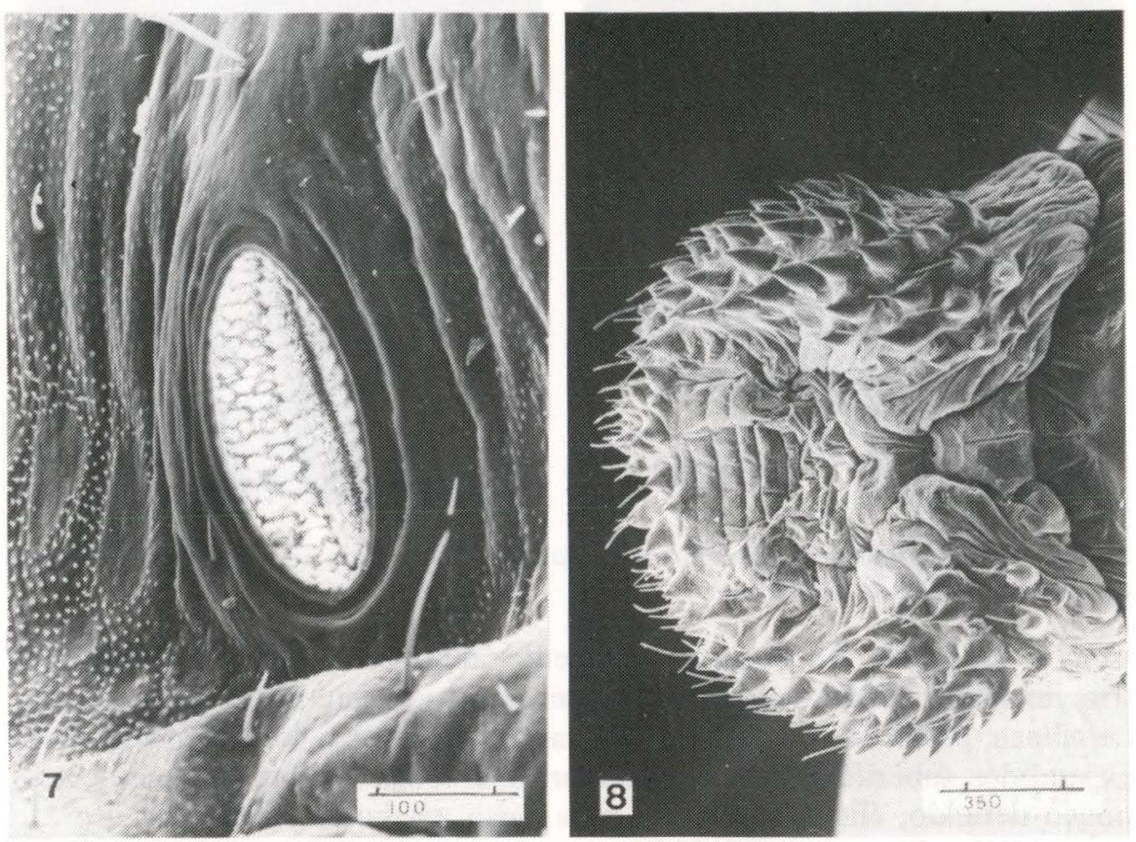

Figs 5-6. Larva de P. melanospidus. (5) Placa pronotal com micro-sulcos; (6) terceira ampola dorsal do abdome com microespinhos próximos às articulações; (a) ampliação da ragião dos microespinhos.

PUPA

Medidas (fêmea/macho): comprimento total, 20,2/17,8; comprimento do vértice, $0,7 / 0,5$; comprimento do tórax, 7,8/6,3; largura do pronoto, 5,3/4,3; largura do terceiro segmento abdominal, 6,0/4,0; comprimento da cabeça, 6,0/4,7; largura da cabeça, 4,3/3,5.

Fêmea vista dorsal (Fig. 8 ): cabeça com vértice semiesférico; tubérculos antenais proeminentes, digitiformes e voltados para fora; antenas com o escapo tuberiforme e tão longo quanto a cabeça, pedicelo curto e menos dilatado, flagelo filiforme, passando sob as margens do pronoto, ao lado da base dos élitros, sobre os fêmures das pernas anteriores e medianas, e passa para a região 

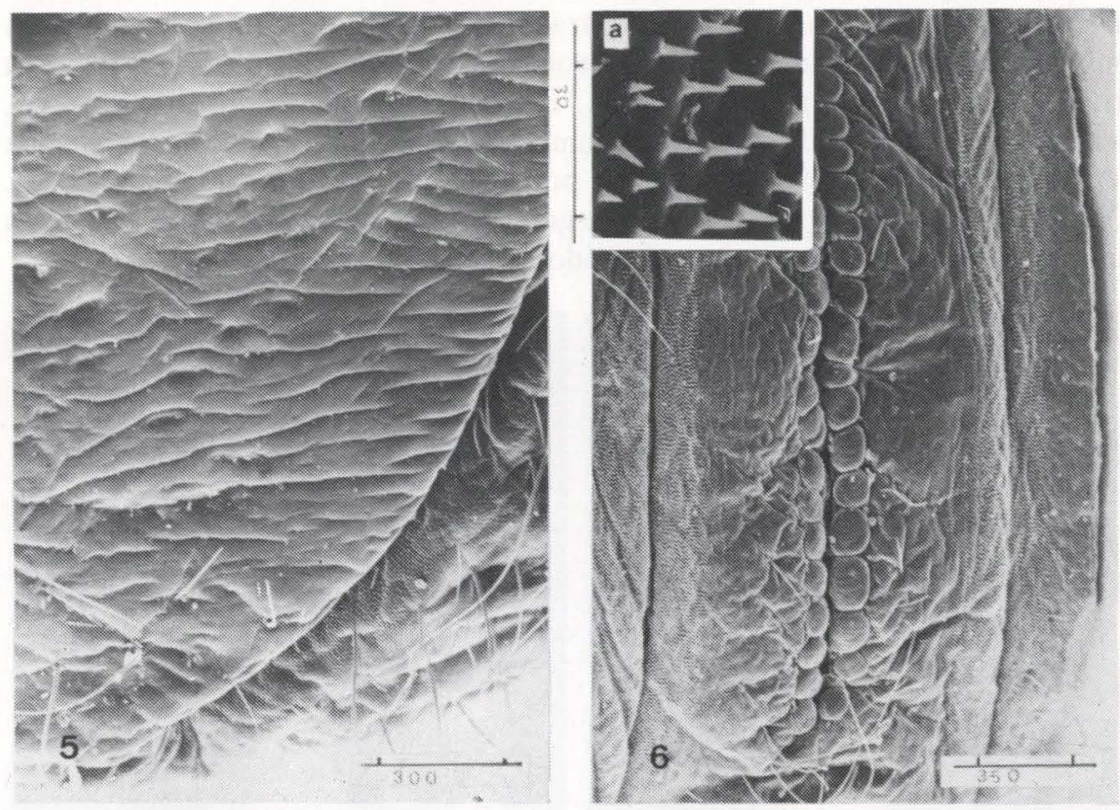

Figs 7-8. P. melanospidus. (7) Terceiro espiráculo abdominal da larva; (8) vista ventral do último segmento abdominal da pupa feminina.

ventral na altura do segundo segmento abdominal. Tórax nitidamente trisegmentado; pronoto semiesférico com depressões laterais, margem anterior curvilínea, posterior recortada e com uma ponta sobre a linha mediana, lados expandidos, tuberiformes, apoiados sobre as antenas. Mesotórax com escutelo pouco definido; élitros inclinados para baixo, passando sob o primeiro e o segundo par de pernas, cobrindo o terceiro par e quase totalmente as asas posteriores; pequenas cavidades irregulares próximo à base, nas imediações do escutelo e na altura dos fêmures anteriores. Metanoto placóide, com a linha mediana conspícua, lados pouco deprimidos e margem posterior curvilínea provida de uma ponta rômbica sobre a linha mediana; asas posteriores encobertas pelos élitros. Abdome coniforme, com o ápice curvo para baixo; os primeiro três segmentos aumentando gradativamente em comprimento, quarto e quinto iguais e do mesmo comprimento do terceiro, o sexto e o sétimo subiguais e levemente mais curtos do que o quinto, o oitavo e o nono curtos e estreitos. Pilosidade rarefeita no vértice, em faixa transversal no ápice e no meio do pronoto, dispersa e irregular nas propleuras, alguns pêlos no meso e metanoto. No abdome espinhos, associados com cerdas, generalizados, tanto em número quanto em tamanho, do primeiro ao último segmento. Pleuras pouco expandidas; seis espiráculos visíveis, obliquamente dispostos e o sétimo vestigial. 
Vista ventral. Cabeça opistognata, com a fronte pouco escavada; genas convexas; clípeo e labro intumescidos; mandíbulas falciformes; palpos maxilares mais longos e mais grossos do que os labiais; antenas visíveis, exceto sob os fêmures anteriores e medianos, passando atrás das tíbias medianas, acompanham a curvatura tíbia-tarso das pernas anteriores e terminam antes do último tarsômero. Pernas anteriores e medianas bem visíveis, as posteriores encobertas pelas asas, exceto a articulação fêmur-tibial e últimos tarsômeros; asas posteriores pouco visíveis. Abdome com quatro segmentos após os tarsômeros; último segmento com o ápice truncado, circundado por um anel incompleto em alto relevo, no centro com excrescências e sulcos transversais; coxitos invisíveis. Pilosidades esparsas na fronte, tufos na ponta do labro, nas mandíbulas e no ápice dos fêmures; uma faixa transversal na base do labro. Arestas pleurais do abdome e semi-anel distal com espinhos, acompanhados de cerdas, robustos, esclerotinizados e ruivos.

Macho. Menor do que a fêmea. Tubérculos antenais digitiformes mais longos e inclinados para fora; vértice rebaixado; antenas mais longas, com o primeiro flagelômero nitidamente dilatado, curvatura posterior da antena na altura da tíbia posterior e termina sobre as pernas anteriores em anel incompleto. Último segmento abdominal com o anel mais fechado do que o da fêmea e pouco mais intumescido; excrescências interanelares menos salientes e desprovidas de espinhos e cerdas.

\section{REFERÊNCIAS BIBLIOGRÁFICAS}

GIACOMEL, F. 1991. Nova espécie de Psylotoxus Thomson, 1968 do Mato Grosso (Coleoptera, Cerambycidae). Acta Biol. Par. 20 (1/4): 1-5.

Recebido em 02XI.1992; aceito em 07.VI.1993. 